\title{
Genetic diversity of old and local apple cultivars of North Caucasus from VIR collection based on SSR markers
}

\author{
Trifonova A.A. ${ }^{1 *}$, Shlyavas A.V. ${ }^{2}$, Boris K.V. ${ }^{1}$, Kudryavtsev A.M. ${ }^{1}$ \\ ${ }^{1}$ Vavilov Institute of General Genetics Russian Academy of Sciences, Moscow, Russia \\ ${ }^{2}$ N.I. Vavilov All-Russian Institute of Plant Genetic Resources (VIR), St. Petersburg, Russia \\ *email:aichka89@mail.ru
}

At the Maikop Experiment Station of VIR a collection of about 160 old and local apple cultivars is maintained, including 41 cultivars from North Caucasus collected during the research expeditions since 1930. These cultivars are known for their ecological plasticity, stable yield, durability and disease and pests resistance. No genetic diversity studies of the collection were previously carried out. To study genetic polymorphism of 41 North Caucasus old and local apple cultivars, ten SSR markers were used. Analysis was performed on ABI Prism 3130xl (Applied Biosystems). We found three genotypes with three alleles at more than one locus, therefore considering them as triploids (Vegetativnoe silnorosloe, Kihar ich Zimniy, Funtovka).Two accessions had identical SSR profiles (Tyazhelka \# 1 and Tyazhelka \# 2). A high level of polymorphism of North Caucasus cultivars was revealed. For diploids, 113 alleles were detected. The number of alleles per locus varied from $6(\mathrm{CHO} 2 \mathrm{CO} 2 b)$ to $20(\mathrm{CHO} 2 \mathrm{cO} a \mathrm{a})$ and averaged 11.3. The polymorphic information content (PIC) ranged from $0.63(\mathrm{CHO2cO2b})$ to 0.91 $(\mathrm{CHO2cO2a})$. The average expected heterozygosity $\left(\mathrm{H}_{\mathrm{e}}\right)$ was 0.81 . High frequency of rare $(13.3 \%)$ and unique $(30.1 \%)$ alleles was detected. Dice genetic similarity coefficient varied from 0.88 (for Kihar ich Letniy and Hruk ich Letniy) to 0 (for 13 pairs of studied accessions) and averaged 0.26 . Cluster analysis did not reveal clear differentiation of the studied cultivars based on their origin except for seven accessions from Dagestan. Thus, the analyzed collection of old and local North Caucasus apple cultivars showed high genetic diversity and the obtained data may be used for SSR genotyping of the accessions.

Acknowledgements: The work was supported by RFBR project No. 17-29-08020. 